\title{
Cyclopropanes via an Efficient 3-Exo Trig Radical Cyclisation Reaction1
}

\author{
Adusumilli Srikrishna,* G. Veera Raghava Sharma and Parthasarathy Hemamalini \\ Department of Organic Chemistry, Indian Institute of Science, Bangalore - 560 012, India
}

The first examples of an exclusive formation of a cyclopropane via the 3-exo trig radical cyclisation of homoallyl bromides 13 and 14 are reported.

The formation of a $1: 1$ mixture of norbornene 1 and nortricyclene 2 from norbornenyl bromide 3 (eqn. 1) is, perhaps, the only example of a homoallyl-cyclopropylmethyl radical rearrangement (via 3-exo trig cyclisation, eqn. 2), 2,3 where a stable cyclopropane system was isolated in reasonable yields under standard radical cyclisation conditions. ${ }^{4}$ One reason extended for the isolation of 2 in this reaction is the large strain in norbornene itself. $\dagger$ However, the higher homologue, the bicyclo[2.2.2]octenyl system 7, did not undergo cyclisation (eqn. 3). $4 b \dagger$ The presence of stabilising

$\div$ According to molecular mechanics calculations, the strain energy $(\triangle \mathrm{SE}$ ) increase going from norbornene to nortricyclene is 21.43 kcal mol-1 as against an increase of $26.93 \mathrm{kcal} \mathrm{mol}^{-1}$ for the simple but-1-ene to cyclopropylmethane $(1 \mathrm{cal}=4.184 \mathrm{~J})$. The strain energy increase from bicyclo[2.2.2] octene ( $\left.\triangle \mathrm{SE} 23.49 \mathrm{kcal} \mathrm{mol}^{-1}\right)$ and from bicyclo[3.2.1]octene $\left(\Delta \mathrm{SE} 23.38 \mathrm{kcal} \mathrm{mol}^{-1}\right)$ to tricyclo[3.2.1.0 $\left.0^{2,7}\right]$ octane is intermediate between these values. groups, such as phenyl (eqn. $2, \mathrm{R}=\mathrm{Ph}$ ) induced the cyclopropane formation, albeit in low yield $(\leq 10 \%) \cdot{ }^{3}$ Indeed, radicals were conveniently used to cleave cyclopropanes to homoallyl systems. 5 We now report the first examples of the ready formation of a cyclopropane, in the tricyclo[3.2.1.0 $\left.0^{2,7}\right]$ octane system $\mathbf{8}$, starting from either a bicyclo[2.2.2] oct-5-en-2-yl radical 7 or a bicyclo[3.2.1]oct-6-en-2-yl radical 9 via 3-exo trig radical cyclisation.

In line with the earlier observation (eqn. 3$)^{4 b}$ radical reaction of the bromide $\mathbf{1 0}$, obtained from $(S)$-carvone as depicted in Scheme 1, under standard radical cyclisation conditions $\left[\mathrm{Bu}_{3} \mathrm{n}_{3} \mathrm{SnH}, \mathrm{AIBN}\right.$ (AIBN = azoisobutyronitrile), $0.02 \mathrm{~mol} \mathrm{dm} \mathrm{dm}^{-3}$ in benzene] resulted in only the reduced product 11 as a mixture of diastereoisomers. The absence of any detectable amount of $\mathbf{1 2}$ indicates the nonexistence of any equilibrium between the initial radical formed with a cyclised radical (e.g., eqn. 3). However, the presence of a stabilising group (e.g., aryl) on the alkene changed the situation. 
<smiles>BrC1CC2C=CC1C2Br</smiles><smiles>C1=CC2CCC1C2</smiles><smiles>C1C2CC3CC1C3C2</smiles>

(1)<smiles>[R]C([R])=CC([X])(C)C=C</smiles><smiles>[R]C([R])=CCC([Y])[Y]</smiles><smiles>CC(C)(C)C(C)(C)C</smiles><smiles>CC12C=CC(CC1=O)C(C)(Br)C2</smiles>

10
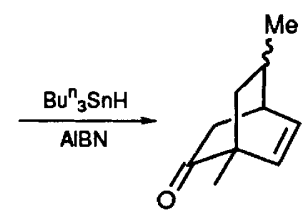

11

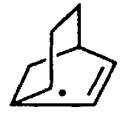

9

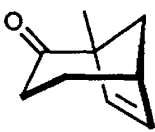

12
Refluxing a $0.02 \mathrm{~mol} \mathrm{dm}^{-3}$ benzene solution of a $3: 1$ mixture of bromides 13a and 14a with $\mathrm{Bu}_{3}{ }_{3} \mathrm{SnH}$ (1.1 equiv.) in the presence of a catalytic amount of AIBN furnished exclusively the cyclopropane product $\mathbf{1 5 a}$, in $85 \%$ yield, in a stereospecific manner (Scheme 1$) \div$ The structure of 15a was clearly delineated from its spectral data $\S$ in particular the absence of alkenic protons and carbons (except the aromatic signals) in the ${ }^{1} \mathrm{H}$ and ${ }^{13} \mathrm{C}$ NMR spectra, and further confirmed by comparison of the ${ }^{1} \mathrm{H}$ and ${ }^{13} \mathrm{C}$ NMR data with those of unsubstituted compound. ${ }^{6}$ The cyclisation takes place so readily that even the presence of 20 equivalents of a radicophile, e.g., methyl acrylate, in the medium was not able to trap the initial radical and stop the cyclopropane formation. The generality of this cyclisation was established by the preparation of $15 \mathbf{a}-\mathbf{e}$ and the results are summarized in Table 1. Interestingly not only aryl groups, but even an acetylene group (entry e) stabilise the radical enough to produce only 15 e.

$\ddagger$ The ${ }^{1} \mathrm{H}$ NMR spectrum of the crude reaction mixture (no alkenic signals) ruled out the presence of any trace amounts of uncyclised products. The ${ }^{13} \mathrm{C}$ NMR spectrum of the compound 15a clearly established the presence of only one stereoisomer and we assigned, tentatively, the phenyl group as endo, since the endo-isomer is slightly more stable than the exo-isomer.

§ Selected spectroscopic data: 1,5-Dimethyl-6-phenyitricyclo[3.2.1.0 ${ }^{2,7}$ ]octan-4-one 15a. The stereochemistry of the phenyl group is tentative. Low melting (below room temperature) solid, b.p. $180^{\circ} \mathrm{C}$ (bath temperature), at 0.2 torr; $[\alpha]_{\mathrm{D}}-140^{\circ}\left(\mathrm{CHCl}_{3}, c 1.1\right)$; IR (neat) $\mathrm{v} / \mathrm{cm}^{-1} 3060,1720,760$ and $710 ;{ }^{1} \mathrm{H}$ NMR $\left(270 \mathrm{MHz}, \mathrm{CDCl}_{3}\right): \delta 7.25$ $(5 \mathrm{H}$, br s, ArH), $3.45(1 \mathrm{H}, \mathrm{d}, J 2.5 \mathrm{~Hz}, 6-\mathrm{H}), 2.68(1 \mathrm{H}$, dd, $J 20.5,2.2$ $\mathrm{Hz}, 3 \mathrm{a}-\mathrm{H}), 2.53(1 \mathrm{H}, \mathrm{dd}, J 20.5,2.7 \mathrm{~Hz}, 3 \mathrm{~b}-\mathrm{H}), 1.93$ and $1.99(2 \mathrm{H}$, $\mathrm{ABq}, J 12.9 \mathrm{~Hz}, 8-\mathrm{H}), 1.48(1 \mathrm{H}, \mathrm{dd}, J 7.3,2.9 \mathrm{~Hz}, 7-\mathrm{H}), 1.35(3 \mathrm{H}, \mathrm{s}$, $1-\mathrm{Me}), 1.19(1 \mathrm{H}, \mathrm{m}, 2-\mathrm{H})$ and $1.11(3 \mathrm{H}, \mathrm{s}, 5-\mathrm{Me}) ;{ }^{13} \mathrm{C}$ NMR $(22.5$ $\mathrm{MHz}, \mathrm{CDCl}_{3}$ ) $\delta 210.9$ (s, C-4), 139.1, (s), $128.1(2 \mathrm{C}, \mathrm{d}), 127.5(2 \mathrm{C}, \mathrm{d})$ and 126.8 (d) (aromatic), 55.9 (s, C-5), 53.7 (d, C-6), 43.2 (t, C-3), 34.8 (t, C-8), 26.7 (d, C-7), 20.2 (s, C-1), 19.5 (q, Me), 18.2 (d, C-2) and $17.3(\mathrm{q}, \mathrm{Me})$; Mass $\mathrm{m} / \mathrm{z} 226\left(100, \mathrm{M}^{+}\right), 198(18), 184(25), 183$ (31), 169 (35), 157 (47), 129 (32), 115 (33), 107 (25), 96 (89), 91 (61) and 77 (27); M, 226.1362.<smiles>[R]C1=C(C)C(=O)C[C@H](C(=C)C)C1</smiles>

16

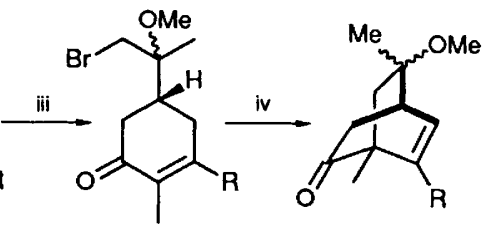

17



vi<smiles>[R]C1=C[C@H]2CC(=O)[C@H]1CC2(C)Br</smiles>

13

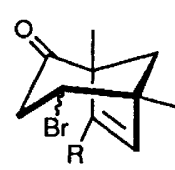

14 a; $\mathrm{R}=\mathrm{Ph}$

b; $\mathrm{R}=p-\mathrm{MeC}_{6} \mathrm{H}_{4}$

c; $\mathrm{R}=p-\mathrm{MeOC}_{6} \mathrm{H}_{4}$

d; $\mathrm{R}=o-\mathrm{MeOC}_{6} \mathrm{H}_{4}$

e; $\mathrm{R}=\mathrm{PhC} \equiv \mathrm{C}$

Scheme 1 Reagents and conditions: $\mathrm{i}, \mathrm{RMgBr}, \mathrm{Et}_{2} \mathrm{O}, 0^{\circ} \mathrm{C}$ to room temp., $6 \mathrm{~h}$, or $\mathrm{RLi}$, THF, $-78^{\circ} \mathrm{C}$ to room temp., $6 \mathrm{~h}$; ii, PCC, silica gel, $\mathrm{CH}_{2} \mathrm{Cl}_{2}$, room temp., $8 \mathrm{~h}$; iii, $\mathrm{N}$-bromosuccinimide, $\mathrm{CH}_{2} \mathrm{Cl}_{2}-$ $\mathrm{MeOH}(3: 2), 0{ }^{\circ} \mathrm{C}$ to room temp., $16 \mathrm{~h}$; iv, $\mathrm{K}^{+}-\mathrm{OBu}^{\mathrm{t}}, 1: 1$ $\mathrm{Bu}^{\mathrm{t} O H}$-THF $\left(0.5 \mathrm{~mol} \mathrm{dm}{ }^{-3}\right), 0^{\circ} \mathrm{C}$ to room temp., $16 \mathrm{~h} ; \mathrm{v}, \mathrm{BBr}_{3}$, $\mathrm{CH}_{2} \mathrm{Cl}_{2},-60^{\circ} \mathrm{C}, 1 \mathrm{~h}$; vi, Bun ${ }_{3} \mathrm{SnH}$, AIBN, $\mathrm{C}_{6} \mathrm{H}_{6}\left(0.02 \mathrm{~mol} \mathrm{dm}{ }^{-3}\right)$, reflux, $2.5 \mathrm{~h}$

Table 1 Yields of various compounds $(\%)^{a}$

\begin{tabular}{lllllll}
\hline Entry & $\mathrm{R}$ & $\mathbf{1 6}^{b}$ & $\mathbf{1 7}^{c}$ & $\mathbf{1 8}^{c}$ & $\mathbf{1 3}$ and 14ף & $\mathbf{1 5}$ \\
\hline $\mathrm{a}$ & $\mathrm{Ph}$ & 75 & 60 & 76 & 78 & 85 \\
$\mathrm{~b}$ & $p$-tolyl & 70 & 68 & 90 & 50 & 93 \\
$\mathrm{c}$ & $p$-anisyl & 55 & 87 & 70 & 45 & 85 \\
$\mathrm{~d}$ & 0 -anisyl & $60^{d}$ & 70 & 60 & 55 & 60 \\
$\mathrm{e}$ & -C $\equiv \mathrm{C}-\mathrm{Ph}$ & 50 & 70 & 68 & 55 & 82 \\
\hline
\end{tabular}

$a^{a}$ Yields refer to isolated and chromatographically pure compounds. All the compounds exhibited satisfactory analytical and spectral data. ${ }^{b}$ Overall yield from $(S)$-carvone. ${ }^{c} 1: 1$ mixture of diastereoisomers. ${ }^{d}$ The corresponding RLi was prepared via orthometallation of anisole in THF (tetrahydrofuran) and TMEDA (tetramethylethylene diamine).

The radical precursors 13 and 14 were obtained from $(S)$-carvone as depicted in Scheme 1. Alkylative 1,3-enone transposition $^{7}$ of $(S)$-carvone, i.e., 1,2 addition of $\mathrm{RLi}$ (or $\mathrm{RMgBr}$ ) followed by oxidation [pyridinium chlorochromate (PCC)-silica gel] of the resulting allylic tertiary alcohol, furnished $\beta$-substituted carvones 16. Transformation of $\mathbf{1 6}$ to the bicyclic compound $\mathbf{1 8}$ was achieved according to the recently developed 8 procedure, via regiospecific bromomethoxylation (to 17) followed by an intramolecular alkylation $\left(\mathrm{K}^{+}-\mathrm{OBu}^{\mathrm{t}-\mathrm{Bu}} \mathrm{u}^{\mathrm{O}} \mathrm{OH}-\mathrm{THF}\right)$ reaction of the thermodynamic enolate. Treatment of 18 with $\mathrm{BBr}_{3}$ generated an inseparable mixture of bromides 13 and 14. The composition of this mixture varied with the nature of $\mathrm{R}$. Structures of $\mathbf{1 3}$ and 14 were derived from their ${ }^{1} \mathrm{H}$ and ${ }^{13} \mathrm{C} \mathrm{NMR}$ spectroscopic

I The composition of the bromides 13 and 14 varied from batch to batch. However, typical observations are as follows: when $\mathrm{R}=\mathrm{H}$, only 10 was formed; when $\mathrm{R}=\mathrm{Ph}$, a $3: 1$ mixture of $13 \mathrm{a}$ and $14 \mathrm{a}$; when $\mathrm{R}=p$-tolyl, $p$-anisyl or $o$-anisyl a $1: 6$ mixture of 13 and $14(14$ as a mixture of diastereoisomers); and when $\mathrm{R}=-\mathrm{C} \equiv \mathrm{C}-\mathrm{Ph}$ only $13 \mathrm{e}$ were obtained. 
data. Radical cyclisation of the bromide mixtures under standard conditions (except when $\mathrm{R}=\mathrm{H}$ ) furnished, exclusively, the cyclised products 15 irrespective of the composition of 13 and 14. The yields of various intermediates along with the final radical cyclisations are listed in Table 1.

In conclusion, we have described the first examples of the formation of a cyclopropane product via an efficient homoallyl-cyclopropyl methyl radical cyclisation, potentially of synthetic value, which we are investigating.

Received, 7th August 1990; Com. 0/03649H

\section{References}

1 For Part 4 of the series, Chiral Synthons from Carvone, see A. Srikrishna and P. Hemamalini, J. Org. Chem., 1990, 55, 4883.

2 M. Newcomb, A. G. Glenn and W. G. Williams, J. Org. Chem., 1989, 54, 2675 and references cited therein. See also, J. Masnovi, E. G. Samsel and R. M. Bullock, J. Chem. Soc., Chem. Commun., 1989, 1044; J. M. Tanko and R. E. Drumright, J. Am. Chem. Soc., $1990,112,5362$.
3 V. W. Bowry, J. Lusztyk and K. U. Ingold, J. Chem. Soc., Chem. Commun., 1990, 923; T. A. Halgren, M. E. H. Howden; M. E. Medof and J. D. Roberts, J. Am. Chem. Soc., 1967, 89, 3051. See also, Z. Cekovic and R. Saicic, Tetrahedron Lett., 1986, 27, 5893. In all the reports where reasonable yields of cyclopropanes were reported, the corresponding radical was generated directly from the cyclopropyl compound and not via the cyclisation of the homoallyl radical, e.g., see reference 2 .

4 (a) C. R. Warner, R. J. Strunk and H. G. Kuivila, J. Org. Chem., 1966, 31, 3381; (b) J. W. Wilt and A. A. Levin, J. Org. Chem., 1962, 27, 2319; (c) M. M. Martin and D. C. DeJongh, J. Am. Chem. Soc., 1962, 84, 3526; (d) T. A. Halgren, J. L. Firkins, T. A. Fujimoto, H. H. Suzukawa and J. D. Roberts, Proc. Nat. Acad. Sci., USA, 1971, 68, 3216; (e) P. C. Wong and D. Griller, J. Org. Chem., 1981, 46, 2327.

5 D. L. J. Clive and S. Daigneault, J. Chem. Soc., Chem. Commun., $1989,332$.

6 A. J. Ragauskas and J. B. Stothers, Can. J. Chem., 1983, 61, 2254

7 G. Buchi and B. Egger, J. Org. Chem., 1971, 36, 2021; A. Srikrishna and P. Hemamalini, Indian J. Chem., Sect B., 1990, 29, 152.

8 A. Srikrishna and P. Hemamalini, Indian J. Chem., Sect B., 1990, 29, 201. 